\title{
Utilização de recursos multimídia para crianças em contexto hospitalar: uma revisão integrativa
}

Using multimedia resources for children in a hospital context: an integrative review

Uso de recursos multimedia para niños en el contexto de un hospital: una revisión integradora

\section{Simone Regina de Carvalho}

Doutoranda na Universidade de Aveiro, Aveiro, Portugal.

simone.rc.lu@gmail.com

ORCID - https://orcid.org/0000-0002-4751-9796

Paula Ângela Coelho Henriques dos Santos

Professora doutora na Universidade de Aveiro, Aveiro, Portugal.

psantos@ua.pt

ORCID - https://orcid.org/0000-0001-7898-8731

António Augusto de Freitas Gonçalves Moreira

Professora doutora na Universidade de Aveiro, Aveiro, Portugal.

moreira@ua.pt

ORCID - https://orcid.org/0000-0003-0040-2811

\section{André Maurício Cunha Campos}

Professor doutor na Universidade Federal do Rio Grande do Norte, Natal, Rio Grande do Norte, Brasil. andre@dimap.ufrn.br

ORCID - https://orcid.org/0000-0001-5824-2318

Recebido em 5 de maio 2019

Aprovado em 15 de janeiro de 2020

Publicado em 10 de abril de 2020

\section{RESUMO}

O internamento hospitalar em crianças suprime o convívio social e produz isolamento. Tal situação requer o reconhecimento de estratégias que visem superar esta condição e que favoreçam a inclusão. Neste sentindo, a utilização de recursos multimídia pode apresentar-se como estratégia facilitadora, contribuindo para a interação das crianças em seu meio social. $\mathrm{O}$ objetivo deste trabalho é caracterizar pesquisas relacionadas com a utilização de recursos multimídia para crianças, adolescentes, pais e cuidadores em contexto hospitalar. Trata-se de uma revisão integrativa estruturada nas seguintes etapas: definição da questão de pesquisa, estabelecimento de critérios de inclusão e exclusão na busca na literatura, definição das informações a serem extraídas dos estudos, avaliação dos estudos incluídos, interpretação dos resultados e síntese dos dados. O levantamento dos artigos foi efetuado nas bases de dados PUBMED, B-ON, SCOPUS e Web of Science, adotando os descritores multimedia, children e hospital, no espaço temporal compreendido entre 2013 e 2019. A partir dos critérios de exclusão e com base na análise 
http://dx.doi.org/10.5902/1984686X38894

do título e resumo, foram designados, para compor o corpus final de análise, 19 artigos. Os resultados apresentados evidenciam o potencial de utilização de recursos multimídias para crianças em contexto hospitalar. Observou-se que a utilização de tais recursos favoreceu a integração das crianças em procedimentos médicos de forma amena, minimizando o estado de estresse e ansiedade produzido pelo ambiente hospitalar, além de clarificar e orientar os pais e pacientes sobre tais procedimentos de forma a favorecer os seus envolvimentos.

Palavras-chave: Multimídia; crianças; hospital.

\section{ABSTRACT}

Hospitalization in children suppresses social interaction and produces isolation. This situation requires the recognition of strategies aimed at overcoming this condition and favoring inclusion. In this sense, the use of multimedia resources can be presented as a facilitating strategy, contributing to the interaction of children in their social environment. The objective of this work is to delineate the research related to the use of multimedia resources for children, adolescents, parents, and caregivers in a hospital context. This is an integrative review structured in the following stages: definition of the research question, establishment of inclusion and exclusion criteria in the literature search, definition of the information to be extracted from the studies, evaluation of included studies, interpretation of the results and synthesis of the data. The articles were surveyed in the databases PUBMED, B-ON, SCOPUS e Web of Science, adopting the descriptors multimedia, children and hospital in the period between 2013 and 2019. From the exclusion criteria and based on the analysis of the title and abstract, 19 articles were assigned to compose the final corpus of analysis. The results highlighted the potential of using multimedia resources for children in the hospital context. It was observed that the use of such resources favored the integration of children in medical procedures in a mild way, minimizing the state of stress and anxiety produced by the hospital environment, and clarifying and guiding parents and patients about such procedures in order to favor their involvement.

Keywords: Multimedia; children; hospital.

\section{RESUMEN}

La hospitalización en niños suprime la interacción social y produce aislamiento. Esta situación requiere el reconocimiento de estrategias dirigidas a superar esta conditión y favorecer la inclusión. En este sentido, el uso de recursos multimedia se puede presentar como una estrategia facilitadora, que contribuye a la interacción de los niños en su entorno social. El objetivo de este trabajo es caracterizar la investigación relacionada con el uso de recursos multimedia para niños, adolescentes, padres y cuidadores en un contexto hospitalario. Es una revisión integradora estructurada en las siguientes etapas: definición de la pregunta de investigación, establecimiento de criterios de inclusión y exclusión en la búsqueda bibliográfica, definición de la información que se extraerá de los estudios, evaluación de los estudios incluidos, interpretación de los resultados y síntesis de los datos. Los artículos fueron encuestados en las bases de datos PUBMED, B-ON, 
SCOPUS y Web of Science, adoptando los descriptores multimedia, niños y hospitales en el período comprendido entre 2013 y 2019. A partir de los criterios de exclusión y con base en el análisis del título y el resumen, se asignaron 19 artículos para componer el corpus final de análisis. Los resultados presentados resaltan el potencial del uso de recursos multimedia para niños en un contexto hospitalario. Se observó que el uso de tales recursos favoreció la integración de los niños en los procedimientos médicos de una manera moderada, minimizando el estado de estrés y ansiedad producido por el entorno hospitalario, y aclarando y guiando a los padres y pacientes sobre tales procedimientos para favorecerlos la participación.

Palabras clave: Multimedia; niños; hospital.

\section{Introdução}

O contexto hospitalar é percebido pelas crianças como um ambiente hostil e desagradável, podendo produzir ansiedade e sofrimento emocional. Tratando-se de crianças hospitalizadas, o desconforto pode ser ainda maior. Além de produzir mudanças que requerem adaptação ao novo ambiente, tal situação afasta a criança de seu convívio com os amigos e a família. Nesse contexto, a criança vivencia uma sensação de solidão e insegurança que reivindica estratégias para o seu enfrentamento.

Nesse cenário, a utilização de recursos multimídia vem sendo requisitada como aporte para minimizar as consequências advindas das experiências vivenciadas por crianças no ambiente hospitalar. Com o aumento da oferta de recursos disponíveis, pesquisadores têm desenvolvidos inúmeros projetos utilizando a tecnologia na intenção de reduzir as implicações resultantes de tal experiência. As pesquisas nesse segmento prosperam e desenvolvem-se em setores distintos, produzindo avanços (HUNTER; KAIN; FORTIER, 2019; WARREN; 2019).

A evidência científica confirma que a utilização de mídias digitais vem sendo disponibilizada de forma ampla nos diversos segmentos sociais e apresenta-se como promissora em contexto hospitalar (WEEKLY et al., 2018). Estudos relatam que a utilização dos recursos digitais por crianças promove a motivação, diminui a timidez e eleva a autonomia e a autoestima (SOARES; SANTAROSA, 2007). Os dispositivos tecnológicos podem funcionar como elo entre a criança hospitalizada e o meio social, transpondo barreiras impostas pelo internamento hospitalar. Ambientes interativos podem oferecer oportunidades para a descoberta e a formação de novas relações e favorecer as relações interpessoais. Ressaltam-se pesquisas que mostraram resultados positivos 
http://dx.doi.org/10.5902/1984686X38894

sobre a utilização de jogos digitais em áreas distintas da saúde: reabilitação física (SEGALA; OLIVEIRA; BRAZ, 2014; CRUZ; D'ALENCAR; MENUCHI, 2015), tratamento de diabetes (KEMPF; MARTIN, 2013) e tratamento de obesidade (STAIANO; ABRAHAM; CALVERT, 2012). Devido ao número de recursos disponíveis, à crescente produção científica sobre a respetiva adoção em contexto hospitalar e, sobretudo, considerando o modo como eles estão dispostos para crianças e adolescentes, é importante realizar um levantamento dos estudos atuais. Para isso, foram considerados três pontos principais para a formulação das questões de pesquisa: 1) participantes dos estudos; 2) recursos empregados; e 3) tipos de estudos. Para cada ponto, foram delineadas questões norteadoras, a saber: 1) Qual a faixa etária dos participantes e em qual contexto os recursos multimídias foram utilizados?; 2) Quais foram os recursos utilizados e com que objetivo?; e 3) Qual o desenho do estudo, qual o objetivo de cada trabalho e quais os resultados obtidos?

Diante do exposto, o presente artigo tem como objetivo: Caracterizar pesquisas relacionadas com a utilização de recursos multimídia para crianças e adolescentes em contexto hospitalar.

\section{Método}

O método proposto para esse estudo foi a Revisão Integrativa da literatura (RI), que tem por finalidade agregar resultados de pesquisas de maneira sistemática sobre um determinado tema ou questão. Tal método possibilita compilar de forma sintética múltiplos estudos, com delineamento distinto, publicados em um determinado campo do conhecimento e produzir uma ampla análise sobre a literatura disposta, proporcionando o aprofundamento sobre o tema proposto, reduzindo incertezas e evidenciando lacunas (BEYEA; NICOLL, 1998; BROOME, 2000).

Com o propósito de assegurar rigor, o estudo constituiu-se em seis etapas, a saber: definição da questão de pesquisa, estabelecimento de critérios de inclusão e exclusão na busca da literatura, definição das informações a serem extraídas dos estudos, avaliação dos estudos incluídos, interpretação dos resultados e síntese dos dados (MENDES; SILVEIRA; GALVÃO, 2008).

A primeira etapa da revisão abordou a definição do problema com base na formulação das questões norteadoras e da proposição dos objetivos. Essa etapa encaminhou as demais e promoveu a seleção de informações relevantes. Na segunda 
http://dx.doi.org/10.5902/1984686X38894

etapa, que foi efetuada no período de fevereiro e março de 2019, realizou-se a busca dos artigos nas bases de dados. Com vista a garantir a qualidade da pesquisa, foram selecionadas bases de dados com peritagem científica e que dispusessem de material referente à temática proposta. Dessa forma, o levantamento dos artigos foi efetuado nas seguintes bases de dados: PUBMED, B-ON, SCOPUS e Web of Science. Utilizaram-se os descritores Medical Subject Headings (MeSH): multimedia AND children AND hospital.

Para auxiliar na seleção, foram definidos como critérios de inclusão: artigos completos publicados em jornais e periódicos científicos no espaço temporal compreendido entre 2013 e 2019. Justifica-se a delimitação do período por se tratar de um tema que sofre modificações constantes e com intuito de incluir os estudos mais recentes. Os critérios de exclusão dos estudos foram: (i) artigos repetidos em outras bases de dados; (ii) artigos de acesso restrito; (iii) artigos de revisão; e (iv) artigos que se referiam a outras temáticas e outras publicações, como livros, dissertação, guias e atas de conferências.

\section{Resultados}

O levantamento das publicações nas bases de dados delimitadas, adotando os descritores e período pré-definidos, resultou em um total de 302 artigos. A partir dos critérios de exclusão e com base na análise do título e resumo, foram designados 19 artigos para compor o corpus final de análise (ver Tabela 1).

Tabela 1 - Número de artigos encontrados em bases de dados eletrônicas

\begin{tabular}{c|c}
\hline Base de dados & Número total de artigos analisados \\
\hline PUBMED & 117 \\
\hline B-ON & 62 \\
\hline SCOPUS & 114 \\
\hline WEB OF SCIENCE & 9 \\
\hline
\end{tabular}

Fonte: Autoria própria, 2019.

Realizou-se a leitura na íntegra dos artigos que compuseram a amostra final, dispostos no Quadro 2. Estes foram codificados para facilitar a sua caracterização, de acordo com a estrutura a seguir. Para auxiliar a identificação das bases de dados, foi utilizado um caractere maiúsculo no início de cada identificador, representando as bases 
de dados, de acordo com o seguinte esquema: B (B-On), S (Scopus), W (Web of Science) e P (PubMed).

Quadro 1 - Caracterização dos artigos que compuseram o corpus final de análise

(continua)

\begin{tabular}{|c|c|c|c|c|}
\hline \# & Artigo & Ano & Autores & Jornal \\
\hline B1 & $\begin{array}{l}\text { Integrating users in an interactive } \\
\text { video education project: Reframing } \\
\text { the patient-centered strategy of a } \\
\text { cystic fibrosis centre }\end{array}$ & 2014 & $\begin{array}{l}\text { Marcello Aspria; Marleen de Mul; } \\
\text { Samantha Adams; Roland Bal }\end{array}$ & $\begin{array}{l}\text { Communications } \\
\text { of the Association } \\
\text { for Information } \\
\text { Systems - CAIS }\end{array}$ \\
\hline B2 & $\begin{array}{l}\text { Evaluating Triple P Online: A Digital } \\
\text { Parent Training Program for Child } \\
\text { Behavior Problems }\end{array}$ & 2017 & Amit Baumel; Keren Faber & ScienceDirect \\
\hline B3 & $\begin{array}{l}\text { Effect of mobile phone short text } \\
\text { messages on glycemic control in } \\
\text { children with type } 1 \text { diabetes. }\end{array}$ & 2014 & $\begin{array}{c}\text { Bassam Bin-Abbas; Musleh Jabbari; } \\
\text { Abdullah Al-Fares; Abdelmoneim El-Dali; } \\
\text { Fahad Al-Orifi }\end{array}$ & $\begin{array}{c}\text { Journal of } \\
\text { Telemedicine and } \\
\text { Telecare }\end{array}$ \\
\hline B4 & $\begin{array}{l}\text { Using an Educational Multimedia } \\
\text { Application to Prepare Children for } \\
\text { Outpatient Surgeries }\end{array}$ & 2014 & $\begin{array}{l}\text { Sara Fernandes; Patrícia Arriaga; } \\
\text { Francisco Esteves }\end{array}$ & $\begin{array}{c}\text { Health } \\
\text { Communication }\end{array}$ \\
\hline B5 & $\begin{array}{l}\text { Interactive media as a tool for } \\
\text { reducing waiting anxiety at pediatric } \\
\text { rehabilitation hospitals: a randomized } \\
\text { controlled trial }\end{array}$ & 2017 & $\begin{array}{l}\text { Elaine Biddiss ; Tara Joy Knibbe; Darcy } \\
\text { Fehling; Patricia Mckeever; Ashley } \\
\text { Cohen; Amy Mcpherson }\end{array}$ & $\begin{array}{l}\text { Developmental } \\
\text { Medicine \& Child } \\
\text { Neurology }\end{array}$ \\
\hline B6 & $\begin{array}{l}\text { Keeping up with video game } \\
\text { technology: Objective analysis of } \\
\text { Xbox Kinect }{ }^{\mathrm{TM}} \text { and PlayStation } 3 \\
\text { Move }^{\mathrm{TM}} \text { for use in burn rehabilitation. }\end{array}$ & 2014 & $\begin{array}{l}\text { Parry I; Carbullido C; Kawada J; Bagley A; } \\
\text { Sen S; Greenhalgh D; Palmieri T }\end{array}$ & $\begin{array}{l}\text { Burns Journal - } \\
\text { Elsevier }\end{array}$ \\
\hline B7 & $\begin{array}{l}\text { Impact of a multimedia teaching tool } \\
\text { on parental anxiety and knowledge } \\
\text { during the informed consent process. }\end{array}$ & 2018 & $\begin{array}{l}\text { Paton, Elizabeth A.; Davis, Sharon K.; } \\
\text { Gaylord, Nan; Cao, Xueyuan; Gosain, } \\
\text { Ankush. }\end{array}$ & $\begin{array}{l}\text { Pediatric Surgery } \\
\text { International }\end{array}$ \\
\hline B8 & $\begin{array}{l}\text { Can mobile phone multimedia } \\
\text { messages and text messages } \\
\text { improve clinic attendance for } \\
\text { Aboriginal children with chronic otitis } \\
\text { media? A randomised controlled trial. }\end{array}$ & 2014 & $\begin{array}{c}\text { James H Phillips; Christine Wigger; } \\
\text { Jemima Beissbarth; Gabrielle B McCallum; } \\
\text { Amanda Leach; Peter S Morris }\end{array}$ & $\begin{array}{l}\text { Journal of } \\
\text { Paediatrics and } \\
\text { Child Health }\end{array}$ \\
\hline B9 & $\begin{array}{l}\text { Multimedia environment toward } \\
\text { analyzing and visualizing live } \\
\text { kinematic data for children with } \\
\text { Hemiplegia }\end{array}$ & 2014 & Abdur Rahman & $\begin{array}{l}\text { Multimed Tools } \\
\quad \text { Appl }\end{array}$ \\
\hline 310 & $\begin{array}{l}\text { Children centered care: Minimizing } \\
\text { the need for anesthesia with a multi- } \\
\text { faceted concept for MRI in children } \\
\text { aged } 4-6\end{array}$ & 2018 & $\begin{array}{l}\text { Stine B. Runge; Nicolaj L. Christensen; } \\
\text { Kim Jensen; Ib E. Jensen }\end{array}$ & $\begin{array}{c}\text { European Journal } \\
\text { of Radiology }\end{array}$ \\
\hline$\beta 11$ & $\begin{array}{l}\text { From analogue to apps--developing } \\
\text { an app to prepare children for } \\
\text { medical imaging procedures. }\end{array}$ & 2015 & Gigi Williams; Siobhan Greene & $\begin{array}{c}\text { Journal of Visual } \\
\text { Communication in } \\
\text { medicine }\end{array}$ \\
\hline S1 & $\begin{array}{l}\text { Automatic Seizure Detection in a } \\
\text { Mobile Multimedia Framework }\end{array}$ & 2018 & $\begin{array}{c}\text { Ghulam Muhammad; Mehedi Masud; Syed } \\
\text { Umar Amin; }\end{array}$ & IEEE Access \\
\hline W1 & $\begin{array}{l}\text { Improving Community Stroke } \\
\text { Preparedness in the HHS (Hip-Hop } \\
\text { Stroke) Randomized Clinical Trial }\end{array}$ & 2018 & $\begin{array}{c}\text { Olajide Williams; Ellyn Leighton-Herrmann } \\
\text { Quinn; Jeanne Teresi; Joseph P. Eimicke; } \\
\text { Jian Kong; Gbenga Ogedegbe; James } \\
\text { Noble }\end{array}$ & Stroke \\
\hline $\mathrm{P} 1$ & $\begin{array}{l}\text { A Cognitive Approach for Design of a } \\
\text { Multimedia Informed Consent Video } \\
\text { and Website in Pediatric Research }\end{array}$ & 2017 & $\begin{array}{c}\text { Holly Antal; H. Timothy Bunnell; Suzanne } \\
\text { M. McCahan; Chris Pennington; Tim } \\
\text { Wysocki; Kathryn Blake }\end{array}$ & J Biomed Inform \\
\hline
\end{tabular}


http://dx.doi.org/10.5902/1984686X38894

Quadro 1 - Caracterização dos artigos que compuseram o corpus final de análise

(conclusão)

\begin{tabular}{|l|l|c|c|c|}
\hline$\#$ & \multicolumn{1}{|c|}{ Artigo } & Ano & \multicolumn{1}{|c|}{ Autores } & Jornal \\
\hline P2 & $\begin{array}{l}\text { A Review of Apps for Calming, } \\
\text { Relaxation and Mindfulness } \\
\text { Interventions for Pediatric Palliative } \\
\text { Care Patients }\end{array}$ & 2018 & $\begin{array}{l}\text { Taelyr Weekly; Nicole Walker;Jill Beck; } \\
\text { Sean Akers; Meaghann Weaver }\end{array}$ & Children \\
\hline P3 & $\begin{array}{l}\text { Developing and evaluating } \\
\text { multimedia information resources to } \\
\text { improve engagement of children, } \\
\text { adolescents, and their parents with } \\
\text { trials (TRECA study): Study protocol } \\
\text { for a series of linked randomised } \\
\text { controlled trials }\end{array}$ & 2017 & $\begin{array}{l}\text { Jacqueline Martin-Kerry; Peter Bower; } \\
\text { Bridget Young; Jonathan Graffy; Rebecca } \\
\text { Sheridan; lan Watt; Paul Baines; } \\
\text { Catherine Stones; Jennifer Preston; } \\
\text { Steven Higgins; Carrol Gamble; Peter } \\
\text { Knapp. }\end{array}$ & Trials \\
\hline P4 & $\begin{array}{l}\text { Feasibility of an online intervention } \\
\text { (STAK-D) to promote physical } \\
\text { activity in children with type 1 } \\
\text { diabetes: protocol for a randomized } \\
\text { controlled trial }\end{array}$ & 2016 & $\begin{array}{c}\text { Holly Blake; Helen Quirk; Paul Leighton; } \\
\text { Tabitha Randell; James Greening; Boliang } \\
\text { Guo; Cris Glazebrook }\end{array}$ & Trials \\
\hline P5 & $\begin{array}{l}\text { mHealth Supportive Care } \\
\text { Intervention for Parents of Children } \\
\text { with Acute Lymphoblastic Leukemia: } \\
\begin{array}{l}\text { Quasi-Experimental Pre- and Post- } \\
\text { design Study }\end{array}\end{array}$ & 2018 & $\begin{array}{c}\text { Jingting Wang; Doris Howell; Nanping } \\
\text { Shen; Zhaohui Geng; Fulei Wu; Min Shen; } \\
\text { Xiaoyan Zhang; Anwei Xie; Lin Wang; } \\
\text { Changrong Yuan FAAN }\end{array}$ & JMIR mhealth and \\
uhealth \\
P6 & $\begin{array}{l}\text { Use of Mobile Devices and the } \\
\text { Internet for Multimedia Informed } \\
\text { Consent Delivery and Data Entry in a } \\
\text { Pediatric Asthma Trial: Study Design } \\
\text { and Rationale }\end{array}$ & 2015 & $\begin{array}{c}\text { Kathryn Blake; Janet T. Holbrook; Holly } \\
\text { Antal; David Shade; H. Timothy Bunnell; } \\
\text { Suzanne M. McCahan; Robert A. Wise; } \\
\text { Chris Pennington; Paul Garfinkel; Tim } \\
\text { Wysocki }\end{array}$ & $\begin{array}{c}\text { Contemp Clin } \\
\text { Trials }\end{array}$ \\
\hline
\end{tabular}

Fonte: Autoria própria, 2019.

Com a finalidade de estruturar o estudo para a análise dos artigos, foi utilizado um instrumento contendo informações referentes aos questionamentos pré-estabelecidos na primeira etapa. Com isso, a apresentação dos resultados encontra-se organizada por meio de quadros comparativos, de maneira descritiva, separados por faixa etária dos participantes, local onde os estudos foram realizados, contexto em que os estudos foram realizados, tecnologias e metodologias empregues.

\section{Análise dos resultados}

A amostra para análise final foi composta por 19 artigos, todos publicados em periódicos internacionais. No que concerne ao espaço temporal, observou-se que a maior parte das publicações ocorreram em 2014 e 2018, totalizando seis artigos em cada ano, seguidos sequencialmente por quatro em 2017, dois em 2015 e um em 2016, conforme representados na Figura 1. 
http://dx.doi.org/10.5902/1984686X38894

Figura 1 - Quantidade de artigos, por ano, para a análise final

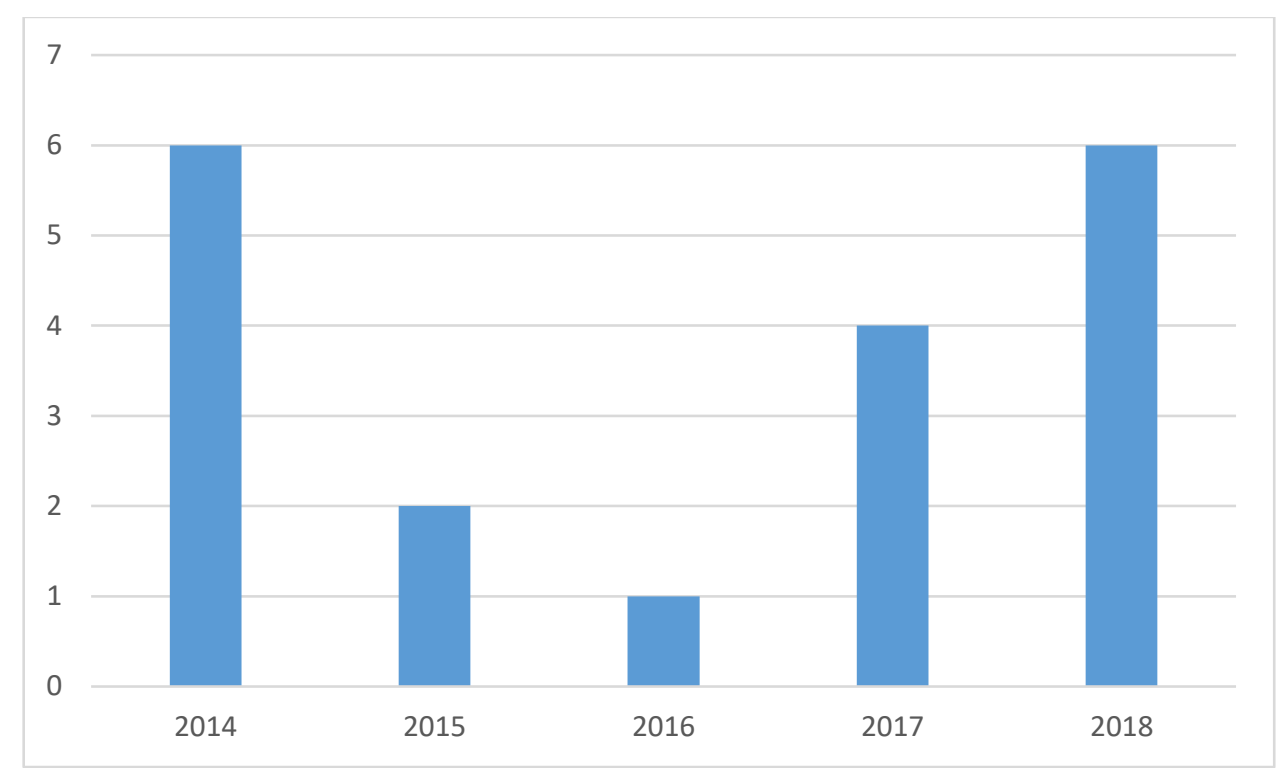

Fonte: Autoria própria, 2019.

Para a caracterização da faixa etária dos participantes, consideramos os limites cronológicos referidos no Estatuto da Criança e do Adolescente - ECA (BRASIL, 1990), que considera "criança" o indivíduo com até 12 anos incompletos, e adolescente o que se situa na faixa etária entre 12 a 18 anos.

Para os dados obtidos nos aspectos relacionados aos participantes dos estudos, identificamos cinco categorias de participantes, nomeadamente: crianças, adolescentes, pais, cuidadores e pacientes, como ilustrado na Figura 2.

Figura 2 - Identificação dos participantes dos estudos

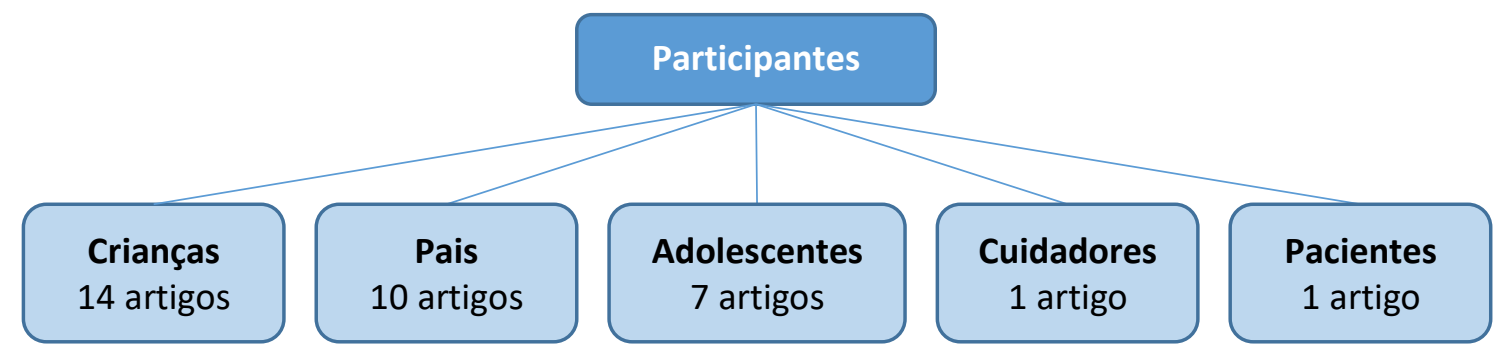

Fonte: Autoria própria, 2019.

Observa-se que prevaleceu a categoria "crianças", presente em 14 estudos (B1, B2, B3, B4, B5, B6, B9, B10, B11, W1, P2, P3, P4, P5), seguida por "pais", com 10 artigos (B2, B4, B5, B7, W1, P1, P2, P3, P5, P6); "adolescentes" (B5, S1, P1, P2, P3, P5, P6); "cuidadores" (B8) e "pacientes" (S1). Importa salientar que, em alguns estudos, há 
http://dx.doi.org/10.5902/1984686X38894

sobreposição de categorias, indicando que um artigo envolve, por exemplo, tanto crianças quanto seus pais.

Com relação ao local e ao contexto onde foram realizadas as pesquisas, a maioria foi realizada na América do Norte, tendo nove deles sido desenvolvidos nos EUA e um no Canadá. Na Europa, foram desenvolvidos quatro trabalhos (Reino Unido, Dinamarca, Portugal e Holanda). Tanto na Ásia quanto na Oceania foram desenvolvidos, respetivamente, dois estudos em cada (China e Arábia Saudita, e Austrália). A Figura 3 apresenta a distribuição descrita. Vale salientar que no estudo P2, por tratar-se de um levantamento de aplicativos para dispositivos móveis (não sendo, portanto, um estudo experimental), não houve uma intervenção em um local específico.

Figura 3 - Distribuição dos estudos por continente

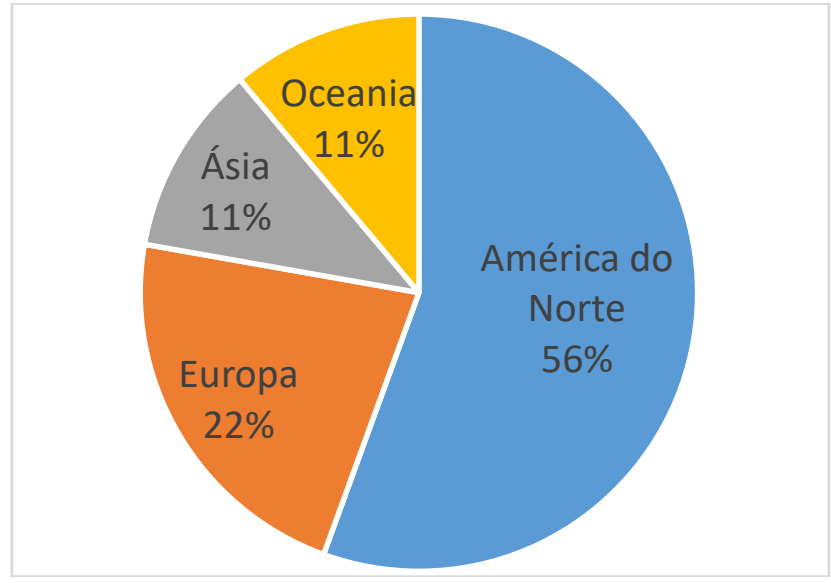

Fonte: Autoria própria, 2019.

Verificou-se que praticamente todos os estudos foram realizados no âmbito hospitalar. Dezoito dos 19 estudos foram realizados em hospitais e/ou clínicas. Apenas um estudo foi realizado em uma escola. A maioria dos trabalhos foram também voltados para a área da saúde. Apenas quatro trabalhos envolviam ou tinham como objetivo processos de ensino e aprendizagem.

Quadro 2 - Quadro informativo referente aos participantes do estudo

\begin{tabular}{|c|c|c|c|c|}
\hline \# & Faixa etária & Local & Contexto & Área \\
\hline B1 & Crianças de 12 a 18 anos e pais & Roterdã, Holanda & $\begin{array}{l}\text { Sophia Children's Hospital } \\
\text { (SCH) }\end{array}$ & Saúde \\
\hline B2 & Crianças de 2 a 9 anos e pais & Nova York, EUA & Hospital pediátrico & Saúde \\
\hline B3 & $\begin{array}{l}\text { Crianças com idade superior a } 4 \\
\text { anos (em média } 11 \text { anos) }\end{array}$ & Arábia Saudita & $\begin{array}{l}\text { Hospital das Forças de } \\
\text { Segurança, em Riyadh }\end{array}$ & Saúde \\
\hline
\end{tabular}


Quadro 2 - Quadro informativo referente aos participantes do estudo

\begin{tabular}{|c|c|c|c|c|}
\hline$\#$ & Faixa etária & Local & Contexto & Área \\
\hline B4 & Crianças de 8 a 12 anos e pais & Lisboa, PT & Hospital & $\begin{array}{l}\text { Saúde e } \\
\text { Educação }\end{array}$ \\
\hline B5 & $\begin{array}{l}\text { Jovens com deficiência (faixa etária } \\
\text { de } 5 \text { a } 19 \text { anos) e pais que } \\
\text { frequentam clínicas ambulatoriais }\end{array}$ & Toronto, CA & $\begin{array}{l}\text { Holland Bloorview Kids } \\
\text { Rehabilitation Hospital }\end{array}$ & Saúde \\
\hline B6 & Crianças entre 5 e 18 anos & Califórnia, US & Hospital & Saúde \\
\hline B7 & $\begin{array}{l}\text { Pais de crianças internadas no } \\
\text { serviço de cirurgia pediátrica de um } \\
\text { hospital infantil }\end{array}$ & Tennessee, US & $\begin{array}{l}\text { University of Tennessee } \\
\text { Health Science Center }\end{array}$ & Saúde \\
\hline B8 & $\begin{array}{l}\text { Cuidadores de Crianças aborígenes } \\
\text { australianas com perfuração da } \\
\text { membrana timpânica }\end{array}$ & $\begin{array}{l}\text { Comunidades } \\
\text { remotas no NE, } \\
\text { AU. }\end{array}$ & $\begin{array}{c}\text { Comunidades remotas no } \\
\text { Território do Norte - NT, } \\
\text { Austrália. }\end{array}$ & Saúde \\
\hline B9 & Crianças com hemiplegia & Nova York, US & Hospital & Saúde \\
\hline B10 & Crianças de 4 a 6 anos & Dinamarca & Hospital & Saúde \\
\hline B11 & Crianças de 4 a 8 anos & Melbourne, AU & The Royal Children's Hospital & $\begin{array}{l}\text { Saúde e } \\
\text { Educação }\end{array}$ \\
\hline S1 & Pacientes entre 10 e 22 anos & MassachusettEUA & \begin{tabular}{|c|} 
Hospital das Crianças de \\
Boston - Instituto de \\
Tecnologia de Massachusetts
\end{tabular} & Saúde \\
\hline W1 & $\begin{array}{l}\text { Crianças entre } 9 \text { e } 12 \text { anos e seus } \\
\text { pais }\end{array}$ & Nova York, US & Escola & Educação \\
\hline P1 & 12 a 17 anos & $\begin{array}{l}\text { Nemours Health } \\
\text { System, US }\end{array}$ & $\begin{array}{l}\text { Hospitais do Sistema de } \\
\text { Saúde Nemours }\end{array}$ & Saúde \\
\hline P2 & Crianças & Não se aplica & Não se aplica & $\begin{array}{c}\text { Saúde } \\
\text { Educação }\end{array}$ \\
\hline P3 & 9 a 17 anos & US & $\begin{array}{c}\text { Clínicas de saúde em } \\
\text { conjunto com } 18 \text { centros de } \\
\text { pesquisa } \\
\end{array}$ & Saúde \\
\hline $\mathrm{P} 4$ & 9 a 12 anos & UK & Clínicas de diabetes & Saúde \\
\hline P5 & Menores de 15 anos & Shangai, $\mathrm{CH}$ & $\begin{array}{c}\text { Hospitais (Centro médico e } \\
\text { Hospital Universitário) }\end{array}$ & Saúde \\
\hline P6 & 12 a 17 anos & $\begin{array}{c}\text { Flórida e Filadélfia, } \\
\text { US }\end{array}$ & Clínicas de saúde (Nemours) & Saúde \\
\hline
\end{tabular}

Fonte: Autoria própria, 2019.

No que concerne aos aspectos relacionados recursos multimídia utilizados, a análise revela que foram referidos nos estudos múltiplos recursos com objetivos distintos. A diversificação das tecnologias utilizadas permitiu que encontrássemos trabalhos usando tecnologias hands free (Kinect e Wii), aplicativos para dispositivos móveis, sistemas baseados na Web e até apresentações PowerPoint como solução metodológica.

O Quadro 3 apresenta uma sinopse das tecnologias e seus respectivos usos nos estudos: 
Quadro 3 - Quadro informativo sobre as tecnologias utilizadas nos estudos

(continua)

\begin{tabular}{|c|c|c|}
\hline \# & Tecnologias utilizadas & Objetivo/ aplicação da tecnologia \\
\hline B1 & $\begin{array}{l}\text { Webcasts ao vivo. WebPEP } \\
\text { ("Programa de Educação de } \\
\text { Pacientes Baseados na Web") }\end{array}$ & $\begin{array}{l}\text { Profissionais de saúde fizeram apresentações sobre aspectos } \\
\text { médicos e psicossociais relacionados à fibrose cística (FC). } \\
\text { Com a intenção de educar e ser educativo para pacientes e } \\
\text { seus pais. }\end{array}$ \\
\hline B2 & $\begin{array}{l}\text { Triple P Online "positive parenting } \\
\text { practices" }\end{array}$ & Ajudar os pais a aprender "práticas parentais positivas". \\
\hline B3 & Mobile phone messages & $\begin{array}{l}\text { Testar a viabilidade de um programa de suporte educacional } \\
\text { por telemedicina usando o serviço de mensagens curtas } \\
\text { (SMS) do celular e avaliar seu efeito no controle glicêmico em } \\
\text { crianças com diabetes tipo } 1 \text {. }\end{array}$ \\
\hline B4 & $\begin{array}{l}\text { Aplicação multimídia educacional; } \\
\text { jogos interativos (videogame) de } \\
\text { computador pessoal (PC) do tablet }\end{array}$ & Preparar as crianças para cirurgias ambulatoriais comuns. \\
\hline B5 & Hands-free Mídia interativa & $\begin{array}{l}\text { A eficácia das mídias na sala de espera na redução da } \\
\text { ansiedade em crianças, incluindo crianças com deficiências. } \\
\text { Mídia interativas projetadas para um jogo acessível e sem o } \\
\text { uso das mãos atenuam a ansiedade de espera e aumentam a } \\
\text { satisfação. }\end{array}$ \\
\hline B6 & $\begin{array}{l}\text { Microsoft Kinect TM (Kinect e Sony } \\
\left.\text { PlayStation } 3 \text { Move }{ }^{\mathrm{TM}}\right)\end{array}$ & $\begin{array}{l}\text { Analisou as demandas de movimentos dos membros } \\
\text { superiores do Kinect e do PS Move usando análise de } \\
\text { movimento tridimensional para determinar sua aplicabilidade } \\
\text { na reabilitação de queimaduras. }\end{array}$ \\
\hline B7 & $\begin{array}{l}\text { Intervenção multimídia utilizada } \\
\text { neste estudo foi uma apresentação } \\
\text { do PowerPoint } \AA\end{array}$ & $\begin{array}{l}\text { Medir o impacto de uma intervenção multimídia (MMI) versus } \\
\text { discussão convencional sobre a compreensão dos pais e } \\
\text { ansiedade durante o processo de consentimento informado } \\
\text { para crianças submetidas a cirurgia para estenose hipertrófica } \\
\text { do piloro. }\end{array}$ \\
\hline B8 & $\begin{array}{l}\text { Mensagens multimídia (vídeos) e } \\
\text { mensagens de texto do celular. As } \\
\text { mensagens foram enviadas usando } \\
\text { o sistema Telstra Online Text Buddy }\end{array}$ & $\begin{array}{l}\text { Enviar mensagens multimídia para famílias de crianças } \\
\text { indígenas com perfuração da membrana timpânica. }\end{array}$ \\
\hline B9 & $\begin{array}{l}\text { Incorpora o ambiente de jogo sério } \\
\text { do Second Life, juntamente com o } \\
\text { Microsoft Kinect }\end{array}$ & $\begin{array}{l}\text { Os autores desenvolveram um jogo de tele-reabilitação para } \\
\text { ser jogado no PS3. Proposta de um ambiente de jogo de } \\
\text { second life especificamente adaptado para crianças } \\
\text { deficientes com Hemiplegia. }\end{array}$ \\
\hline$\beta 10$ & $\begin{array}{l}\text { Aplicativo interativo com elementos } \\
\text { gamification para uso em casa com } \\
\text { o Rumble como guia através de } \\
\text { animações 3D }\end{array}$ & $\begin{array}{l}\text { Preparação de crianças para a realização da ressonância } \\
\text { magnética. }\end{array}$ \\
\hline$\beta 11$ & Aplicativo baseado em jogos & $\begin{array}{l}\text { Desenvolver um aplicativo para preparar crianças para } \\
\text { procedimentos de imagens médicas. }\end{array}$ \\
\hline S1 & Estrutura de saúde móvel multimídia & Detectar sinais de convulsão em eletroencefalograma. \\
\hline W1 & $\begin{array}{l}\text { Hip Hop Stroke (HHS). Intervenção } \\
\text { multimídia }\end{array}$ & $\begin{array}{l}\text { Ensinar e motivar as crianças a compartilhar informações } \\
\text { sobre AVC. }\end{array}$ \\
\hline P1 & Vídeo, website & $\begin{array}{l}\text { Facilitar o acesso à informação sobre doenças e ensaios } \\
\text { clínicos com o objetivo de melhorar a tomada de decisão do } \\
\text { consentimento em ensaios clínicos. }\end{array}$ \\
\hline P2 & $\begin{array}{l}\text { Aplicativos para dispositivos móveis } \\
\text { com recursos audiovisuais }\end{array}$ & $\begin{array}{l}\text { Objetivos diversificados, envolvendo desde jogos a aplicativos } \\
\text { musicais, de exercícios de meditação, yoga, terapia cognitiva } \\
\text { comportamental, monitoramento de sintomas de estresse, } \\
\text { entre outros. }\end{array}$ \\
\hline P3 & $\begin{array}{l}\text { Vídeos, animações, textos e } \\
\text { formulários interativos na Web }\end{array}$ & $\begin{array}{l}\text { Melhor informar e ajudar na tomada de decisão de possíveis } \\
\text { participantes em ensaios clínicos. }\end{array}$ \\
\hline
\end{tabular}


http://dx.doi.org/10.5902/1984686X38894

Quadro 3 - Quadro informativo sobre as tecnologias utilizadas nos estudos

(conclusão)

\begin{tabular}{|l|l|l|}
\hline$\#$ & \multicolumn{1}{|c|}{ Tecnologias utilizadas } & \multicolumn{1}{c|}{ Objetivo/ aplicação da tecnologia } \\
\hline P4 & Sistema Web (STAK-D) & $\begin{array}{l}\text { Promoção de atividades físicas através de elementos } \\
\text { interativos, monitorização de atividades físicas, } \\
\text { demonstrações em vídeo de rotinas de atividades, servindo } \\
\text { também como canal de comunicação de pais e crianças com } \\
\text { profissionais. }\end{array}$ \\
\hline P5 & $\begin{array}{l}\text { Aplicativo para dispositivo móvel e } \\
\text { rede social (WeChat) }\end{array}$ & $\begin{array}{l}\text { Prover informações sobre leucemia e dar suporte sobre o } \\
\text { andamento do tratamento, de cuidados e assistência social. }\end{array}$ \\
\hline P6 & $\begin{array}{l}\text { Aplicativo para dispositivo móvel e } \\
\text { sistema Web com vídeos }\end{array}$ & $\begin{array}{l}\text { Obter consentimento para participação em ensaios clínicos, } \\
\text { reduzindo infraestrutura especializada, visitas e como meio de } \\
\text { monitoramento do estudo. }\end{array}$ \\
\hline
\end{tabular}

Fonte: Autoria própria, 2019.

Por fim, o Quadro 4 apresenta uma síntese do desenho metodológico, dos objetivos e dos resultados obtidos em cada um dos estudos analisados.

Quadro 4 - Quadro informativo sobre as tecnologias utilizadas nos estudos

(continua)

\begin{tabular}{|c|c|c|c|}
\hline$\#$ & Desenho & Objetivos do estudo & Resultados/conclusões \\
\hline B1 & $\begin{array}{l}\text { Relato de } \\
\text { avaliação } \\
\text { formativa }\end{array}$ & $\begin{array}{l}\text { Avaliar o projeto WebPEP (“Web- } \\
\text { Based Patient Education } \\
\text { Program”). Analisar como os } \\
\text { pacientes com fibrose cística } \\
\text { foram "integrados” no aplicativo } \\
\text { WebPEP, partindo da noção } \\
\text { personalização do usuário. }\end{array}$ & $\begin{array}{l}\text { A avaliação mostrou uma falha entre os } \\
\text { usuários potenciais e reais no projeto } \\
\text { WebPEP; A personalização do aplicativo } \\
\text { em relação aos seus usuários deu nova } \\
\text { legitimação ao projeto. Um único artefato } \\
\text { tecnológico pode estar envolvido em } \\
\text { diferentes práticas coexistentes de } \\
\text { centralização no paciente. }\end{array}$ \\
\hline B2 & $\begin{array}{l}\text { Ensaio clínico } \\
\text { controlado } \\
\text { randomizado }\end{array}$ & $\begin{array}{l}\text { Ajudar os pais a aprender } \\
\text { "práticas parentais positivas" } \\
\text { (PPP), promovendo } \\
\text { comportamentos de cuidado dos } \\
\text { pais, gerenciamento de } \\
\text { comportamentos inadequados, um } \\
\text { ambiente de baixo conflito, } \\
\text { confiança dos pais e bem-estar } \\
\text { social e emocional das crianças. }\end{array}$ & $\begin{array}{l}\text { Identificou-se como recurso valioso e } \\
\text { importante para famílias que buscam } \\
\text { tratamento baseado em evidências para } \\
\text { problemas de comportamento infantil. Pode } \\
\text { ser usado de forma independente por pais } \\
\text { interessados, fora das configurações } \\
\text { tradicionais de cuidados de saúde ou } \\
\text { projetos de pesquisa. É distribuído a um } \\
\text { preço que é comparável ou inferior ao } \\
\text { preço de uma sessão de terapia com um } \\
\text { terapeuta certificado. }\end{array}$ \\
\hline B3 & $\begin{array}{l}\text { Ensaio } \\
\text { experimental } \\
\text { prospectivo }\end{array}$ & $\begin{array}{l}\text { Testar a viabilidade de um } \\
\text { programa de suporte educacional } \\
\text { por telemedicina usando o serviço } \\
\text { de mensagens curtas (SMS) do } \\
\text { celular e avaliar seu efeito no } \\
\text { controle glicêmico em crianças } \\
\text { com diabetes tipo } 1 .\end{array}$ & $\begin{array}{l}\text { Mensagens de telefones celulares, tanto } \\
\text { educativas quanto interativas, podem ser } \\
\text { úteis no apoio ao autogerenciamento do } \\
\text { diabetes em crianças e adolescentes. }\end{array}$ \\
\hline
\end{tabular}


Quadro 4 - Quadro informativo sobre as tecnologias utilizadas nos estudos

(continua)

\begin{tabular}{|c|c|c|c|}
\hline \# & Desenho & Objetivos do estudo & Resultados/conclusões \\
\hline B4 & $\begin{array}{l}\text { Aplicação } \\
\text { multimídia } \\
\text { educacional } \\
\text { (uma aventura } \\
\text { no hospital) }\end{array}$ & $\begin{array}{l}\text { Testar a eficácia de uma aplicação } \\
\text { multimídia interativa sobre as } \\
\text { emoções pré-operatórias das } \\
\text { crianças e suas preocupações } \\
\text { com a hospitalização e cirurgia. } \\
\text { Medir os efeitos sobre a } \\
\text { ansiedade do estado parental. }\end{array}$ & $\begin{array}{l}\text { As crianças que usaram esse instrumento } \\
\text { educacional relataram menos } \\
\text { preocupações com a cirurgia em todas as } \\
\text { dimensões de preocupação pré-operatória, } \\
\text { em contraste com as crianças nos grupos } \\
\text { de comparação e controle. A aplicação } \\
\text { multimídia educacional afeta positivamente } \\
\text { o nível cognitivo, mas não afeta a criança } \\
\text { emocionalmente. os pais do grupo } \\
\text { experimental relataram um estado de } \\
\text { ansiedade menor do que os pais no grupo } \\
\text { controle. }\end{array}$ \\
\hline B5 & $\begin{array}{l}\text { Ensaio } \\
\text { controlado } \\
\text { randomizado }\end{array}$ & $\begin{array}{l}\text { Investigar a eficácia da mídia na } \\
\text { sala de espera para reduzir a } \\
\text { ansiedade e aumentar a } \\
\text { satisfação em um hospital } \\
\text { pediátrico de reabilitação. }\end{array}$ & $\begin{array}{l}\text { A mídia interativa reduziu a ansiedade de } \\
\text { espera pré-clínica em jovens com } \\
\text { deficiência. Mídia interativa era acessível a } \\
\text { jovens com mobilidade variada. A mídia } \\
\text { interativa aumentou a satisfação dos pais e } \\
\text { da equipe na clínica. Foram propostas } \\
\text { diretrizes para projetos de mídias } \\
\text { interativas inclusivas (hands-free) para } \\
\text { instalações de saúde. }\end{array}$ \\
\hline B6 & $\begin{array}{l}\text { Aplicação de } \\
\text { videogames } \\
\text { interativos } \\
\text { (Kinect e PS3) } \\
\text { na reabilitação } \\
\text { de queimados }\end{array}$ & $\begin{array}{l}\text { Usar a análise de movimento } \\
\text { tridimensional para avaliar a } \\
\text { tecnologia de videogame } \\
\text { interativo, especificamente o } \\
\text { Microsoft Kinect (Microsoft) e o } \\
\text { Sony PlayStation } 3 \text { Move (Sony) } \\
\text { para determinar sua aplicabilidade } \\
\text { na reabilitação de queimados. }\end{array}$ & $\begin{array}{l}\text { As demandas físicas por amplitude de } \\
\text { movimento do ombro e do cotovelo ao } \\
\text { jogar o Kinect e, em menor escala, o PS } \\
\text { Move são comparáveis ao movimento } \\
\text { funcional necessário para tarefas diárias, } \\
\text { como comer com um utensílio e pentear o } \\
\text { cabelo. Os videogames comercialmente } \\
\text { disponíveis mostram potencial terapêutico } \\
\text { na reabilitação de queimados. }\end{array}$ \\
\hline B7 & $\begin{array}{l}\text { Série temporal } \\
\text { interrompida. } \\
\text { Quase- } \\
\text { experimental }\end{array}$ & $\begin{array}{l}\text { Medir o impacto de uma } \\
\text { intervenção multimídia (MMI) } \\
\text { versus discussão convencional } \\
\text { sobre a compreensão dos pais e } \\
\text { ansiedade durante o processo de } \\
\text { consentimento informado para } \\
\text { crianças submetidas a cirurgia em } \\
\text { estenose hipertrófica do piloro. }\end{array}$ & $\begin{array}{l}\text { O MMI reduziu significativamente a } \\
\text { ansiedade dos pais durante o processo de } \\
\text { consentimento. }\end{array}$ \\
\hline B8 & $\begin{array}{l}\text { Estudo } \\
\text { controlado } \\
\text { randomizado }\end{array}$ & $\begin{array}{l}\text { Avaliar a eficácia de mensagens } \\
\text { multimídia por celular para famílias } \\
\text { de crianças indígenas com } \\
\text { perfuração da membrana timpânica } \\
\text { (TMP) na promoção da saúde. }\end{array}$ & $\begin{array}{l}\text { Embora não tenha havido melhora na } \\
\text { assistência clínica ou na saúde auditiva, este } \\
\text { ensaio controlado randomizado de } \\
\text { mensagens multimídia em línguas indígenas } \\
\text { demonstrou ser uma forma culturalmente } \\
\text { apropriada de promoção da saúde. }\end{array}$ \\
\hline
\end{tabular}


http://dx.doi.org/10.5902/1984686X38894

Quadro 4 - Quadro informativo sobre as tecnologias utilizadas nos estudos

(continua)

\begin{tabular}{|c|c|c|c|}
\hline$\#$ & Desenho & Objetivos do estudo & Resultados/conclusões \\
\hline B9 & $\begin{array}{l}\text { Os autores } \\
\text { desenvolveram } \\
\text { um jogo de tele- } \\
\text { reabilitação para } \\
\text { ser jogado no } \\
\text { PS3 e Kinect. }\end{array}$ & $\begin{array}{l}\text { Apresentar um ambiente } \\
\text { multimídia capaz de capturar } \\
\text { dados cinemáticos de movimentos } \\
\text { comuns de uma criança com } \\
\text { incapacidade hemiplégica e gerar } \\
\text { resultados analíticos ao vivo como } \\
\text { parte do sistema de tomada de } \\
\text { decisão de um terapeuta. O } \\
\text { ambiente multimídia incorpora o } \\
\text { ambiente de jogo sério do Second } \\
\text { Life, juntamente com o Microsoft } \\
\text { Kinect, onde o movimento } \\
\text { terapêutico ao vivo da criança e o } \\
\text { terapeuta são sincronizados entre } \\
\text { o mundo físico e virtual. }\end{array}$ & $\begin{array}{l}\text { Usando hardware de sensor Kinect 3D } \\
\text { disponível no mundo virtual do Second Life, } \\
\text { desenvolvemos um ambiente multimídia que } \\
\text { pode rastrear diferentes gestos projetados } \\
\text { para um paciente hemiplégico registrado } \\
\text { durante uma sessão de terapia. Usando a } \\
\text { estrutura, um paciente pode visualizar ou } \\
\text { baixar uma sessão de treinamento físico } \\
\text { realizada por um avatar no Second Life que } \\
\text { foi originalmente gravado por um terapeuta. } \\
\text { Usando nosso modelo analítico } \\
\text { desenvolvido, um terapeuta pode visualizar } \\
\text { as métricas de melhoria após analisar os } \\
\text { dados da sessão disponíveis em nosso } \\
\text { repositório on-line projetado }\end{array}$ \\
\hline B10 & $\begin{array}{l}\text { Estudo } \\
\text { experimental } \\
\text { Prospectivo }\end{array}$ & $\begin{array}{l}\text { Avaliar a necessidade de anestesia } \\
\text { geral (GA) em ressonância } \\
\text { magnética (RM) em crianças de } 4 \text { a } \\
6 \text { anos usando um conceito } \\
\text { multifacetado, o Children Centered } \\
\text { Care (CCC), em comparação com } \\
\text { uma configuração padrão. }\end{array}$ & $\begin{array}{l}\text { Com o conceito multifacetado CCC, o uso do } \\
\text { GA para RM em crianças de } 4 \text { a } 6 \text { anos foi } \\
\text { reduzido acentuadamente para } 5 \% \text {. A } \\
\text { qualidade da imagem foi mantida e a } \\
\text { configuração foi custo-efetiva. }\end{array}$ \\
\hline B11 & $\begin{array}{l}\text { Estudo } \\
\text { experimental }\end{array}$ & $\begin{array}{l}\text { Desenvolver um jogo direcionado a } \\
\text { crianças com idade entre } 4 \text { e } 8 \text { anos } \\
\text { para prepará-las para todos os } \\
\text { procedimentos de imagens } \\
\text { médicas. O objetivo é reduzir o } \\
\text { medo antecipatório dos } \\
\text { procedimentos de imagem e } \\
\text { garantir que as crianças } \\
\text { comparecessem a exames de } \\
\text { imagem equipados com as } \\
\text { habilidades necessárias para que } \\
\text { fossem realizadas varreduras } \\
\text { eficientes e eficazes. }\end{array}$ & $\begin{array}{l}\text { O tempo médio gasto para os pacientes } \\
\text { estarem prontos para imagens reduziu; } \\
\text { Os problemas médios de conformidade } \\
\text { foram reduzidos. As taxas médias de } \\
\text { ansiedade (medidas pelos pais e } \\
\text { radiologistas) melhoraram. }\end{array}$ \\
\hline S1 & $\begin{array}{l}\text { Estudo } \\
\text { experimental }\end{array}$ & $\begin{array}{l}\text { Desenvolver um sistema de } \\
\text { detecção de convulsões em uma } \\
\text { estrutura multimídia móvel que } \\
\text { detectasse automaticamente as } \\
\text { condições de convulsão dos } \\
\text { pacientes registrados no sistema. }\end{array}$ & $\begin{array}{l}\text { O sistema alcançou melhor precisão em } \\
\text { comparação com outros sistemas } \\
\text { relacionados na literatura. }\end{array}$ \\
\hline W1 & $\begin{array}{l}\text { Ensaio clínico } \\
\text { randomizado }\end{array}$ & $\begin{array}{l}\text { Capacitar crianças para } \\
\text { reconhecer os sinais do Acidente } \\
\text { Vascular Cerebral (AVC) e } \\
\text { compartilhar informações com os } \\
\text { seus pais. }\end{array}$ & $\begin{array}{l}\text { As crianças do grupo intervenção } \\
\text { apresentaram melhor preparo para o } \\
\text { reconhecimento do AVC; HHS é um modelo } \\
\text { intergeracional eficaz para aumentar a } \\
\text { prontidão para o AVC entre minorias } \\
\text { economicamente desfavorecidas. }\end{array}$ \\
\hline
\end{tabular}


Quadro 4 - Quadro informativo sobre as tecnologias utilizadas nos estudos

(conclusão)

\begin{tabular}{|c|c|c|c|}
\hline \# & Desenho & Objetivos do estudo & Resultados/conclusões \\
\hline P1 & $\begin{array}{l}\text { Metodologia } \\
\text { empírica e as } \\
\text { conclusões foram } \\
\text { sobre } \\
\text { observações dos } \\
\text { próprios autores. }\end{array}$ & $\begin{array}{l}\text { Avaliar a compreensão do } \\
\text { consentimento de ensaio clínico } \\
\text { por pais e adolescentes através } \\
\text { do uso de vídeo e web. }\end{array}$ & $\begin{array}{l}\text { Os autores argumentam sobre a necessidade de } \\
\text { se usar abordagens cognitivas e teorias de } \\
\text { aprendizagem (ex.: princípios de aprendizagem, } \\
\text { teoria de sobrecarga cognitiva, memória de } \\
\text { trabalho etc.) aliadas ao uso de vídeo e material } \\
\text { multimídia para facilitar a compreensão de pais e } \\
\text { crianças de procedimentos em ensaios clínicos. }\end{array}$ \\
\hline P2 & $\begin{array}{l}\text { Avaliação } \\
\text { independente por } \\
3 \text { avaliadores } \\
\text { usando a escala } \\
\text { MARS (Mobile } \\
\text { Application Rating } \\
\text { Scale) }\end{array}$ & $\begin{array}{l}\text { Avaliar aplicativos móveis } \\
\text { voltados a distrair e tranquilizar } \\
\text { pacientes pediátricos. }\end{array}$ & $\begin{array}{l}\text { Vários pacientes já usavam jogos nos celulares } \\
\text { como forma de distração. Porém os aplicativos } \\
\text { mais convincentes incluem aplicativos que } \\
\text { permitem os pais desenharem com os filhos à } \\
\text { distância e aplicativos que permitem os pais } \\
\text { lerem histórias para crianças dormirem à } \\
\text { distância. } 22 \text { aplicativos foram revisados e } \\
\text { mostraram potencial para ajudar no cuidado } \\
\text { paliativo de crianças. }\end{array}$ \\
\hline P3 & $\begin{array}{l}\text { Design } \\
\text { participativo. } \\
\text { Participantes } \\
\text { aleatoriamente } \\
\text { designados em } \\
\text { grupos cruzados. }\end{array}$ & $\begin{array}{l}\text { Apresentar o processo de } \\
\text { desenvolvimento e aplicação de } \\
\text { recursos multimídia para auxiliar } \\
\text { no processo de tomada de } \\
\text { decisão sobre a participação de } \\
\text { crianças em estudos clínicos. }\end{array}$ & $\begin{array}{l}\text { Avaliou-se índices de recrutamento e de } \\
\text { retenção de crianças e adolescentes em } \\
\text { ensaios clínicos. O material multimídia mostrou } \\
\text { potencial para melhor informar sobre as } \\
\text { decisões, bem como providenciou informação } \\
\text { além das decisões dos ensaios. }\end{array}$ \\
\hline P4 & $\begin{array}{l}\text { O artigo não } \\
\text { possui um } \\
\text { desenho } \\
\text { metodológico. Ele } \\
\text { propõe um a ser } \\
\text { seguido em } \\
\text { intervenções } \\
\text { online com } \\
\text { crianças de } 9 \text { a } \\
12 \text { anos. }\end{array}$ & $\begin{array}{l}\text { Apresentar o protocolo de uma } \\
\text { intervenção online com o } \\
\text { objetivo de verificar a viabilidade } \\
\text { da aplicação de um programa } \\
\text { de suporte e motivação de } \\
\text { atividades físicas em crianças } \\
\text { com diabetes tipo } 1 .\end{array}$ & $\begin{array}{l}\text { Propôs-se um estudo com até } 50 \text { crianças de } 9 \\
\text { a } 12 \text { anos com diabetes tipo } 1 \text { (T1DM) a serem } \\
\text { recrutadas em duas clínicas. Eles passam a ter } \\
\text { acesso a um serviço web da intervenção e } \\
\text { monitor de atividade no pulso durante } 6 \text { meses, } \\
\text { com um grupo de controle. Entrevistas foram } \\
\text { igualmente propostas com parte dos } \\
\text { participantes. O protocolo apresentado no artigo } \\
\text { visa estimar a taxa de recrutamento de crianças } \\
\text { e pais, a adesão dos participantes aos } \\
\text { elementos da intervenção (por exemplo, } \\
\text { monitores de atividade nos pulsos), efeitos } \\
\text { adversos da intervenção, coletar informações } \\
\text { de saúde, clínica e econômica, bem como } \\
\text { explorar as razões de não-prosseguimento e } \\
\text { aceitação da intervenção. }\end{array}$ \\
\hline P5 & $\begin{array}{l}\text { Intervenção } \\
\text { quase- } \\
\text { experimental com } \\
\text { pré e pós estudos } \\
\text { envolvendo pais } \\
\text { em dois grupos. }\end{array}$ & $\begin{array}{l}\text { Avaliar a eficiência de uma } \\
\text { intervenção com suporte de um } \\
\text { aplicativo móvel voltado para } \\
\text { saúde (mHealth) em crianças } \\
\text { com leucemia no apoio } \\
\text { emocional em relação aos } \\
\text { cuidados, às incertezas da } \\
\text { doença, na qualidade de vida e } \\
\text { conhecimento. }\end{array}$ & $\begin{array}{l}\text { Os resultados indicam que o uso do aplicativo } \\
\text { reduz a ansiedade dos pais e incertezas sobre } \\
\text { a doença. Ele também melhorou a função social } \\
\text { dos pais, aumento seus conhecimentos sobre a } \\
\text { doença. Resultados qualitativos também } \\
\text { demonstraram a satisfação dos pais com a } \\
\text { intervenção. }\end{array}$ \\
\hline P6 & $\begin{array}{l}\text { Pesquisa } \\
\text { participativa com } \\
\text { diferentes grupos } \\
\text { de pais. }\end{array}$ & $\begin{array}{l}\text { Avaliar o uso de internet e } \\
\text { dispositivos móveis na } \\
\text { condução do processo de } \\
\text { consentimento e visitas de } \\
\text { estudo em ensaios clínicos em } \\
\text { crianças com asma. }\end{array}$ & $\begin{array}{l}\text { O artigo indica que os tratamentos se } \\
\text { encontram em execução, não havendo, } \\
\text { portanto, resultados finais. Porém, indica que a } \\
\text { forma de condução de ensaios clínicos com o } \\
\text { apoio da internet trará benefícios clínicos e } \\
\text { econômicos importantes. }\end{array}$ \\
\hline
\end{tabular}

Fonte: Autoria própria, 2019. 
http://dx.doi.org/10.5902/1984686X38894

\section{Discussão}

O ambiente hospitalar é percebido pelas crianças como um local que produz estresse e ansiedade. Pensando em minimizar esses efeitos, o uso das mídias digitais tem sido concretizado em contextos e situações distintas. De entre os artigos analisados, observou-se que as publicações se referiam ao desenvolvimento de mídias digitais (B9, B11, S1), análise e teste de eficácia e viabilidade (B1, B3, B4, B5, B6, B7, B8, B10) e promoção da educação em saúde (B2, W1).

A elaboração de um recurso tecnológico direcionado para as crianças deve levar em consideração alguns aspectos, tais como: a faixa etária, ambientes propícios (lúdicos), o contexto onde será utilizado, atividades motivadoras, interatividade. Essa preocupação é referida nos estudos (B3, B4, B5, B10, B11, W1, P1). Tais estudos enfatizam a promoção de um ambiente agradável e motivador, adequado ao desenvolvimento de atividades com crianças e adolescentes.

Ressalta-se que a utilização de games promove na criança o sentimento de liberdade de agir, de desfrutar de uma atividade prazerosa, de transpor a imaginação, além de promover autonomia. Os estudos (B4, B5, B6, B9, B10, B11, P2) demonstram essa prática e corroboram as evidências quando apresentam em seus resultados a potencialidade da sua aplicação para crianças no âmbito da saúde. Nos estudos referidos, os games foram propostos no preparo de pacientes para cirurgia (B4); para reduzir a ansiedade (B4, B5); no apoio emocional a crianças com leucemia (P5); na reabilitação de queimados (B6); como atividade terapêutica para crianças hemiplégicas (B9); para reduzir a ansiedade em procedimentos de imagem (B10, B11). Ainda, observou-se a utilização das mídias digitais na promoção de atividades físicas (B9, P4, P6) e na condução de consentimento informado (B7, P6).

Os resultados desses estudos indicam que as atividades lúdicas despertam nas crianças sensações prazerosas, minimizando os efeitos produzidos pela privação da possibilidade de brincar em ambiente livre, produzindo bem-estar. Considera-se relevante a utilização de games e mídias digitais em ambientes hospitalares por promover o vínculo entre as crianças e os profissionais envolvidos, facilitando a socialização e a interação. Somando-se a isso, permite que as crianças experimentem novas situações e incentiva a resolução dos problemas que se apresentam. Assim como, desenvolve o raciocínio, estimula a criatividade e funciona como estratégia coadjuvante para o enfrentamento das situações inconvenientes advindas dos tratamentos de saúde. 
http://dx.doi.org/10.5902/1984686X38894

Salienta-se também que o contexto onde a pesquisa é desenvolvida é de elevada importância. Nos estudos em análise predominou o contexto hospitalar (B1, B2, B3, B4, B5, B6, B7, B8, B9, B10, B11, S1). Por se tratar de um ambiente peculiar, o diferencial do uso da tecnologia no hospital é a possibilidade de reduzir os sentimentos de medo, ansiedade e angústia vivenciados pelas crianças como consequência de sua enfermidade, tratamento e hospitalização. Nesse sentido, a utilização de tais recursos fomenta a prática da humanização em saúde ao impulsionar a valorização do sujeito e a melhoria na qualidade de vida, percebendo o ser em sua integralidade e contemplando a sua subjetividade.

Contudo, nem sempre a implementação dessas práticas na rotina hospitalar será tarefa fácil, sobretudo a inserção dos recursos digitais. A adesão ao uso da tecnologia requer o comprometimento da equipe e pressupõe habilidade e destreza do profissional para utilizar os recursos tecnológicos. Além disso, essas atividades deverão ser incorporadas à rotina complexa dos serviços de saúde.

$\mathrm{Na}$ análise, destaca-se também o estudo (B8) por ter sido o primeiro ensaio clínico realizado em uma comunidade remota aborígene no norte da Austrália que utilizou mensagens de texto para promover a saúde auditiva em populações de alto risco. Esse estudo exemplifica as transformações ocorridas no cenário mundial frente aos avanços exponenciais no âmbito das tecnologias digitais, resultando em novas estratégias de atenção à saúde a fim de promover o acesso e reduzir barreiras geográficas, sociais e/ou culturais. A possibilidade na comunicação e a amplitude de alcance das mídias digitais surgem como recursos potenciais para superar tais barreiras. Porém, convém ressaltar que as dificuldades encontradas ainda em muitas regiões, sobretudo brasileiras, transcendem o acesso à tecnologia e não é apenas a incorporação das tecnologias e mídias digitais que irão reduzir as iniquidades.

\section{Considerações finais}

No decorrer do artigo, observou-se que o contexto hospitalar apresenta-se para as crianças e adolescentes como um ambiente hostil que provoca disruptura tanto em sua dinâmica familiar como em sua rotina, produzindo sentimentos de medo, ansiedade e sofrimento emocional. Dentre as estratégias para o enfrentamento de tal situação, figura a utilização de recursos multimídia. Diante do exposto, na intenção de identificar o que tem sido produzido sobre o tema, realizou-se uma revisão de literatura. 
http://dx.doi.org/10.5902/1984686X38894

Os resultados apresentados evidenciam o potencial da utilização das mídias digitais para crianças em contexto hospitalar. As propostas analisadas nos estudos apresentaram um conjunto diversificado de aplicações multimídia destinadas a crianças e a adolescentes, assim como a seus pais.

Evidenciou-se que a utilização de tais recursos favoreceu a integração das crianças em procedimentos médicos de forma amena, minimizando o estado de estresse e ansiedade produzido pelo ambiente hospitalar. Os estudos apontam ainda a capacidade de clarificar e orientar os pais e pacientes sobre tais procedimentos, de forma a favorecer o seu envolvimento.

Contudo, como toda prática inovadora, a implementação de recursos multimídia em ambiente hospitalar enfrenta desafios. Por se tratar de um contexto peculiar, requer para a efetivação dessa prática profissionais e equipes comprometidas capazes de reconhecer as potencialidades disponíveis nos recursos digitais e na sua aplicação através de estratégias distintas, que possam promover os melhores resultados. Os estudos analisados dispõem de referenciais teóricos que podem contribuir para novas pesquisas, cuja intenção seja investigar e desenvolver estratégias com a utilização dos recursos multimídias para promoção da inclusão, assim como para minimizar as consequências inconvenientes produzidas pelas experiências vivenciadas pelas crianças em contexto hospitalar.

\section{Referências}

BEYEA, Suzanne; NICOLL, Leslie. Writing an integrative review. Aorn Journal, [s.I.], v. 67, n. 4, p.877-880, abr. 1998. Wiley. http://dx.doi.org/10.1016/s0001-2092(06)62653-7.

BRASIL. Casa Civil - Subchefia para Assuntos Jurídicos. Lei № 8.069 - Dispõe sobre o Estatuto da Criança e do Adolescente e dá outras providências. Brasília, DF, 1990.

BROOME Marion. Integrative literature reviews for the development of concepts. In: Rodgers B. L., Knafl, K. A., editors. Concept development in nursing: foundations, techniques and applications. Philadelphia (USA): W.B Saunders Company; p.231-250, 2000. Disponível em:

https://www.researchgate.net/publication/238248432_Integrative_literature_reviews_for_th e_development_of_concepts. Acesso em: 28 fev. 2019.

CRUZ, Rafael Vinícius Santos; D’ALENCAR, Matheus Santos; MENUCHI, Marcus Rodrigo Trindade Pinheiro. A utilização do nintendo wiiß como ferramenta terapêutica em programas de reabilitação traumato-ortopédica: uma revisão de literatura. Revista Pesquisa em Fisioterapia. v. 5, n. 02, p. 153-162. 2015. Disponível em: https://www5.bahiana.edu.br/index.php/fisioterapia/article/view/596 Acesso em: 26 out. 2019 
HUNTER, John; KAIN, Zeev; FORTIER, Michelle. Pain relief in the palm of your hand: Harnessing mobile health to manage pediatric pain. Pediatr Anesth. v. 29, p.120-124, 2019. https://doi.org/10.1111/pan.13547

KEMPF, Kerstin; MARTIN, Stephan. Autonomous exercise game use improves metabolic control and quality of life in type 2 diabetes patients - a randomized controlled trial. Bmc Endocrine Disorders, [s.I.], v. 13, n. 1, p.1-9, dez. 2013. Springer Nature. http://dx.doi.org/10.1186/1472-6823-13-57.

MENDES, Karina dal Sasso; SILVEIRA, Renata Cristina de Campos Pereira; GALVÃO, Cristina Maria. Método de pesquisa para a incorporação de evidências na saúde e na enfermagem: revisão integrativa. Texto Contexto: Enfermagem, Florianópolis, v. 17, n. 2, p.758-764, dez. 2008. Disponível em: http://www.scielo.br/pdf/tce/v17n4/18.pdf Acesso em: 28 fev. 2019.

SEGALA, Marina; OLIVEIRA, Giselle de Camargo; BRAZ, Melissa Medeiros. Utilização do Nintendo Wiiß como recurso terapêutico no tratamento da paralisia cerebral: uma revisão integrativa. Saúde: Santa Maria, Santa Maria, v. 40, n. 01, p.15-20, jan. 2014. Disponível em: https://periodicos.ufsm.br/revistasaude/article/view/8261. Acesso em: 28 fev. 2019.

SOARES, Marlene da Silva; SANTAROSA, Lucila Maria Costi. A motivação de crianças hospitalizadas para o uso dos Ambientes Digitais Virtuais. In: WEI XIII WORKSHOP SOBRE INFORMÁTICA NA ESCOLA, 2007, Rio de Janeiro. Anais do XXVII Congresso SBC., 2007. p.430-432.

STAIANO, Amanda; ABRAHAM, Anisha; CALVERT, Sandra. The Wii Club: Gaming for Weight Loss in Overweight and Obese Youth. Games For Health Journal, [s.I.], v. 1, n. 5, p.377-380, out. 2012. http://dx.doi.org/10.1089/g4h.2012.0052.

WARREN, Jillian. Exploring the Potential for Tangible Social Technologies for Childhood Cancer Patients within the Hospital. In INTERNATIONAL CONFERENCE ON TANGIBLE, EMBEDDED, AND EMBODIED INTERACTION (TEI '19). 2019, New York, NY, USA, p. 733-736 2019. https://doi.org/10.1145/3294109.3302956

\section{Referências da revisão}

ANTAL, Holly et al. A cognitive approach for design of a multimedia informed consent video and website in pediatric research. Journal of Biomedical Informatics. v. 66, p.248258, fev. 2017. Elsevier BV. http://dx.doi.org/10.1016/j.jbi.2017.01.011.

ASPRIA, Marcello et al. Integrating users in an interactive video education project: Reframing the patient-centered strategy of a cystic fibrosis centre. Communications of the Association for Information Systems, v. 34, n. 23, p.439-452, jan. 2014.

BAUMEL, Amit; FABER, Keren. Evaluating Triple P Online: A Digital Parent Training Program for Child Behavior Problems. Cognitive And Behavioral Practice, [s.I.], v. 25, n. 4, p.538-543, nov. 2018. Elsevier BV. http://dx.doi.org/10.1016/j.cbpra.2017.10.001.

BIDDISS, Elaine et al. Interactive media as a tool for reducing waiting anxiety at paediatric 
rehabilitation hospitals: a randomized controlled trial. Developmental Medicine \& Child Neurology, [s.I.], v. 60, n. 6, p.602-610, 15 dez. 2017. Wiley. http://dx.doi.org/10.1111/dmcn.13646.

BIN-ABBAS, Bassam et al. Effect of mobile phone short text messages on glycaemic control in children with type 1 diabetes. Journal of Telemedicine And Telecare, [s.I.], v. 20, n. 3, p.153-156, 18 mar. 2014. SAGE Publications.

http://dx.doi.org/10.1177/1357633x14529244.

BLAKE, Holly et al. Feasibility of an online intervention (STAK-D) to promote physical activity in children with type 1 diabetes: protocol for a randomised controlled trial. Trials, [s.I.], v. 17, n. 1, p.1-14, 8 dez. 2016. Springer Nature. http://dx.doi.org/10.1186/s13063016-1719-0.

BLAKE, Kathryn et al. Use of mobile devices and the internet for multimedia informed consent delivery and data entry in a pediatric asthma trial: Study design and rationale. Contemporary Clinical Trials, [s.I.], v. 42, p.105-118, maio 2015. Elsevier BV. http://dx.doi.org/10.1016/j.cct.2015.03.012.

FERNANDES, Sara; ARRIAGA, Patrícia; ESTEVES, Francisco. Using an Educational Multimedia Application to Prepare Children for Outpatient Surgeries. Health Communication, [s.I.], v. 30, n. 12, p.1190-1200, 21 ago. 2014. Informa UK Limited. http://dx.doi.org/10.1080/10410236.2014.896446.

MARTIN-KERRY, Jacqueline et al. Developing and evaluating multimedia information resources to improve engagement of children, adolescents, and their parents with trials (TRECA study): Study protocol for a series of linked randomised controlled trials. Trials, v. 18, n. 1, p.1-12, 8 jun. 2017. Springer Nature. http://dx.doi.org/10.1186/s13063-017-1962z.

MUHAMMAD, Ghulam et al. Automatic Seizure Detection in a Mobile Multimedia Framework. IEEE Access, [s.I.], v. 6, p.45372-45383, 2018. Institute of Electrical and Electronics Engineers (IEEE). http://dx.doi.org/10.1109/access.2018.2859267.

PARRY, Ingrid et al. Keeping up with video game technology: Objective analysis of Xbox Kinect $^{\mathrm{TM}}$ and PlayStation 3 Move $^{\mathrm{TM}}$ for use in burn rehabilitation. Burns, [s.I.], v. 40, n. 5, p.852-859, ago. 2014. Elsevier BV. http://dx.doi.org/10.1016/j.burns.2013.11.005.

PATON, Elizabeth et al. Impact of a multimedia teaching tool on parental anxiety and knowledge during the informed consent process. Pediatric Surgery International, [s.I.], v. 34, n. 12, p.1345-1352, 25 set. 2018. Springer Nature. http://dx.doi.org/10.1007/s00383018-4352-z.

PHILLIPS, James et al. Can mobile phone multimedia messages and text messages improve clinic attendance for Aboriginal children with chronic otitis media? A randomised controlled trial. Journal of Paediatrics and Child Health, [s.I.], v. 50, n. 5, p.362-367, 25 fev. 2014. Wiley. http://dx.doi.org/10.1111/jpc.12496.

RAHMAN, M. Abdur. Multimedia environment toward analyzing and visualizing live 
kinematic data for children with Hemiplegia. Multimedia Tools And Applications, [s.I.], v. 74, n. 15, p.5463-5487, 1 fev. 2014. Springer Science and Business Media LLC. http://dx.doi.org/10.1007/s11042-014-1864-y.

RUNGE, Stine et al. Children centered care: Minimizing the need for anesthesia with a multi-faceted concept for MRI in children aged 4-6. European Journal Of Radiology, [s.l.], v. 107, p.183-187, out. 2018. Elsevier BV. http://dx.doi.org/10.1016/j.ejrad.2018.08.026.

WANG, Jingting et al. MHealth Supportive Care Intervention for Parents of Children With Acute Lymphoblastic Leukemia: Quasi-Experimental Pre- and Postdesign Study. Jmir Mhealth And Uhealth. v. 6, n. 11, p.195-207, 19 nov. 2018. JMIR Publications Inc.. http://dx.doi.org/10.2196/mhealth.9981.

WEEKLY, Taelyr et al. A Review of Apps for Calming, Relaxation, and Mindfulness Interventions for Pediatric Palliative Care Patients. Children. v. 5, n. 2, p.2-6, 26 jan. 2018. MDPI AG. http://dx.doi.org/10.3390/children5020016.

WILLIAMS, Gigi; GREENE, Siobhan. From analogue to apps - developing an app to prepare children for medical imaging procedures. Journal of Visual Communication In Medicine, [s.I.], v. 38, n. 3-4, p.168-176, 2 out. 2015. Informa UK Limited. http://dx.doi.org/10.3109/17453054.2015.1108285.

WILLIAMS, Olajide et al. Improving Community Stroke Preparedness in the HHS (Hip-Hop Stroke) Randomized Clinical Trial. Stroke, [s.I.], v. 49, n. 4, p.972-979, abr. 2018. Ovid Technologies (Wolters Kluwer Health). http://dx.doi.org/10.1161/strokeaha.117.019861.

\section{Correspondência}

Simone Regina de Carvalho - UNICEUNA - Centro Universitário Natalense, Av. Prudente de Morais, 4.890, Lagoa Nova, Natal, Rio Grande do Norte - Brasil CEP: $59063-200$

\section{(i) (3)}

This work is licensed under a Creative Commons Attribution-NonCommercial 4.0 International (CC BY-NC 4.0) 